\title{
Effects of adrenalectomy on photoperiod-induced changes in release of luteinizing hormone and prolactin in ovariectomized ewes
}

\author{
K. K. Schillo, M. A. Green and S. H. Hayes \\ Department of Animal Sciences, University of Kentucky, Lexington, KY 40546-0215, U.S.A.
}

\begin{abstract}
Summary. Finnish Landrace $\times$ Southdown ewes were ovariectomized (OVX) and subjected to daily photoperiods of 16L:8D (Group I) or 8L:16D (Group II) for 84 days. Ewes were then either adrenalectomized $(\mathrm{ADX})(\mathrm{N}=5$ for Group $\mathrm{I} ; \mathrm{N}=4$ for Group II) or sham ADX ( $N=6$ for Groups I + II). After surgery, ewes in Group I were subjected to $8 \mathrm{~L}: 16 \mathrm{D}$ for 91 days and 16L:8D for 91 days whereas ewes in Group II were exposed to 16L:8D for 91 days and $8 \mathrm{~L}: 16 \mathrm{D}$ for 91 days. Oestradiol implants were inserted into all ewes on Day 148. Sequential blood samples were taken at 28, 56, 91, 119,147 and 168 days after surgery to determine secretory profiles of LH and prolactin. Photoperiod did not influence LH release in Group $\mathbf{I}$ in the absence of oestradiol. Although photoperiod influenced frequency and amplitude of LH pulses in Group II before oestradiol treatment, adrenalectomy did not prevent these changes in patterns of LH release. However, in Group II the increase in $\mathrm{LH}$ pulse amplitude during exposure to long days was greater $(P<0.01)$ in adrenalectomized ewes than in sham-operated ewes. Mean concentrations of LH increased in ADX ewes on Days $91(P=0.07)$ and $119(P<0.05)$. Adrenalectomy failed to influence photoperiod-induced changes in mean concentrations of $\mathrm{LH}$, amplitude of $\mathrm{LH}$ pulses and frequency of $\mathrm{LH}$ pulses in the presence of oestradiol. Concentrations of prolactin were influenced by photoperiod. In Groups I and II concentrations of prolactin increased $(P<0.01)$ after adrenalectomy, but the magnitude of this effect decreased over time. These results suggest that the effects of photoperiod on patterns of $\mathrm{LH}$ release are mediated in part by a mechanism that is not dependent on sex steroids and that the adrenal may influence release of prolactin.
\end{abstract}

Keywords: photoperiod; LH; prolactin; adrenalectomy; sheep

\section{Introduction}

The effects of photoperiod on reproduction in the ewe may be mediated by two neuroendocrine mechanisms. A sex steroid-dependent mechanism involves photoperiod-induced changes in responsiveness of the hypothalamic-pituitary axis to the negative feedback action of oestradiol (Legan et al., 1977; Legan \& Karsch, 1980). During the breeding season oestradiol is a weak inhibitor of luteinizing hormone (LH) pulse amplitude but increases frequency of LH pulses (Goodman \& Karsch, 1980; Karsch et al., 1983). In contrast, oestradiol becomes a potent inhibitor of LH pulse frequency during anoestrus (Goodman et al., 1982; Martin et al., 1983). Recent evidence suggests that oestradiol exerts its negative feedback action on secretion of gonadotrophin-releasing hormone in the sheep (Karsch et al., 1987).

Photoperiod also influences patterns of LH release in ovariectomized ewes not treated with oestradiol (sex steroid-independent effects). Ovariectomized ewes subjected to natural short daylengths had higher LH pulse frequencies and lower LH pulse amplitudes than did ovariectomized 
ewes exposed to natural long daylengths (Goodman et al., 1982). Similar results have been reported for ovariectomized ewes exposed to artificial photoperiods (Pau \& Jackson, 1985; Schillo et al., 1985).

The existence of a sex steroid-independent effect of photoperiod has not been proven because seasonal fluctuations in patterns of $\mathrm{LH}$ release in ovariectomized ewes may be attributed to changes in responsiveness to negative feedback actions of adrenal oestrogens (MacDonald \& Siiteri, 1965; Warren \& Cheatum, 1967) or androgens (Abraham, 1974) which can be aromatized to form oestrogens in the brain and other tissues (Naftolin \& Ryan, 1975). We tested the hypothesis that sex steroid-independent effects are due to feedback actions of adrenal sex steroids by studying the effects of adrenalectomy on photoperiod-induced changes in patterns of $\mathrm{LH}$ release in ovariectomized ewes. We also studied the effects of adrenalectomy on photoperiod-induced changes in prolactin release because previous work suggests that the adrenal gland influences prolactin release in rats (Robyn \& Tukumbane, 1983; Krieg et al., 1984).

\section{Materials and Methods}

Animals. Adult, Finnish Landrace $\times$ Southdown ewes were used. All 24 ewes were maintained on pasture before being placed in photochambers where they were fed alfalfa hay, and had access to water and trace mineralized salt.

Treatments. Ewes were assigned randomly to one of two treatment groups (Fig. 1). All ewes were ovariectomized on 12 and 13 September 1985. After surgery, ewes were placed into photochambers. Ewes in Group I were exposed to daily photoperiods of $16 \mathrm{~h}$ light: $8 \mathrm{~h}$ dark (16L:8D; long days) for 84 days, $8 \mathrm{~L}: 16 \mathrm{D}$ (short days) for 91 days and $16 \mathrm{~L}: 8 \mathrm{D}$ for 91 days. Ewes in Group II were exposed to 8L:16D for 84 days, 16L:8D for 91 days and 8L:16D for 91 days. Using automatic timers, lights were turned on at $04: 00 \mathrm{~h}$ and off at $20: 00 \mathrm{~h}$ during long-day treatments and on at $08: 00 \mathrm{~h}$ and off at 16:00 h for short-day treatments. Ambient temperature was maintained at $20^{\circ} \mathrm{C}$ throughout the experiment.

The experiment began after the initial 84-day period. Animals were subjected to bilateral adrenalectomy or sham adrenalectomy during the final 17 days of this period (3-20 December 1985). There were 6 sham-operated ewes in Groups I and II. Numbers of adrenalectomized ewes in Groups I and II were 5 and 4, respectively, because of losses due to surgery.

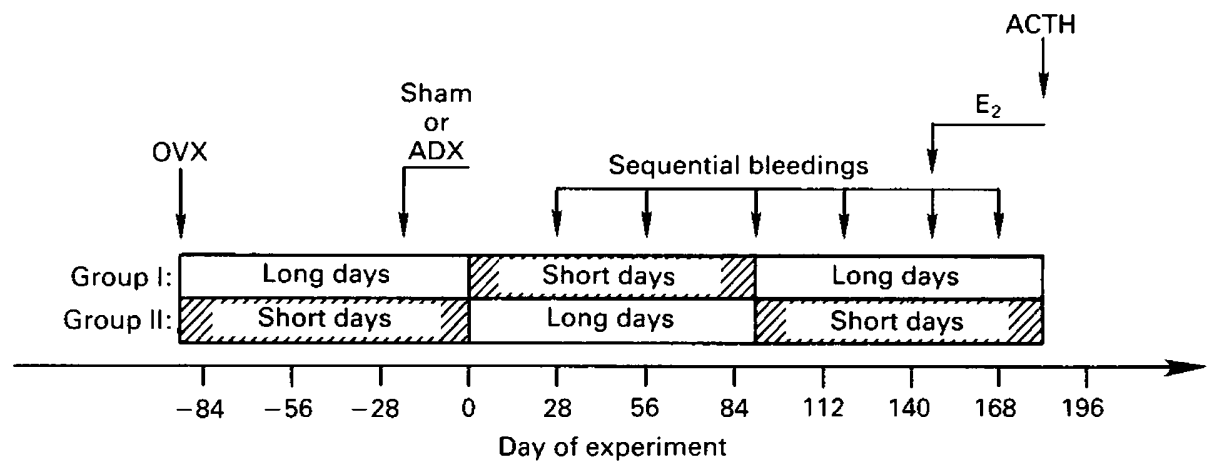

Fig. 1. Experimental design used to determine the effects of adrenalectomy (ADX) on photoperiod-induced changes in release of luteinizing hormone and prolactin in ovariectomized (OVX) ewes (see text for details).

Blood samples were taken at 10-min intervals for $4 \mathrm{~h}$ between $11: 30$ and $15: 30 \mathrm{~h}$ (sequential bleeding) at $28,56,91$, 119 and 147 days to assess patterns of $\mathrm{LH}$ release. Serum concentrations of prolactin were measured in samples taken at 60-min intervals during these first 5 sequential bleedings. On Day 148, a Silastic (Dow Corning, Midland, MI, U.S.A.) capsule containing $10 \mathrm{~mm}$ packed oestradiol- $17 \beta(1.47 \mathrm{~mm}$ i.d. $\times 1.96 \mathrm{~mm}$ o.d.) was implanted subcutaneously in the axillary region under the right front leg of each sheep. This type of implant produced serum concentrations of $\sim 1 \mathrm{pg} / \mathrm{ml}$ (Goodman et al., 1982). On Day 168, animals were subjected to an additional sequential bleeding to evaluate the effects of adrenalectomy on $\mathrm{LH}$ release in the presence of oestradiol.

The following procedure was used to determine whether adrenalectomies were complete. At the conclusion of the experiment all sheep were injected intramuscularly with $40 \mathrm{U}$ adrenocorticotrophic hormone (ACTH; Butler, Columbus, OH, U.S.A.). Blood samples were taken $15 \mathrm{~min}$ before injection, immediately before injection, and at 15 , $45,75,105,165$ and $195 \mathrm{~min}$ after injection to determine serum concentrations of cortisol. 
Surgery. Ovariectomies were performed via midventral laparotomy using sodium thiamylal to induce anaesthesia and halothane to maintain anaesthesia. Each ewe was given intramuscular injections containing $60000 \mathrm{U}$ penicillin and $600000 \mathrm{U}$ streptomycin (Combiotic, Butler, Columbus, OH, U.S.A.) on the day of surgery, and on each of 5 consecutive days after surgery.

Bilateral adrenalectomies were performed according to the procedure described by Thompson \& Wagner (1974). Adrenals were removed by a two-step procedure which required two horizontal incisions, one on each side of the ewe along the transverse processes of the lumbar vertebrae. In sham-operated ewes, adrenals were isolated, then manipulated, but were not removed. All ewes received antibiotic therapy as described for ovariectomies. Adrenalectomized ewes received replacement therapy of $0.2 \mathrm{mg}$ dexamethasone and $2.5 \mathrm{mg} 11$-deoxycorticosterone acetate intramuscularly each day at $\sim 09: 00 \mathrm{~h}$ throughout the experiment. Dexamethasone replacement therapy was withdrawn $24 \mathrm{~h}$ before each sequential bleeding. Ewes were haltered and tethered $1 \mathrm{~h}$ before and during bleeding periods. Blood samples $(5 \mathrm{ml})$ were taken via jugular venepuncture.

Radioimmunoassays. Blood samples were allowed to clot overnight at $4^{\circ} \mathrm{C}$ and serum was recovered and stored at $-20^{\circ} \mathrm{C}$ until assayed. Serum concentrations of $\mathrm{LH}$ were determined by the method of Niswender et al. (1969) using ovine $\mathrm{LH}$ antiserum (GDN-15) at an initial dilution of 1:50 000 (200 $\mu \mathrm{l})$. NIADDK-oLH-25 was used for radioiodination and as a standard. Precipitation of bound hormone was accomplished by using goat antirabbit gamma globulin (Biotek Research, Inc., Lenexa, KS, U.S.A.) at an initial dilution of 1:50 (100 $\mu \mathrm{l})$. Parallelism was demonstrated by showing that estimates of $\mathrm{LH}$ concentration were not influenced by volume of serum assayed $(25-200 \mu \mathrm{l})$. Recoveries of $0 \cdot 5,1,2,4,8$ and $16 \mathrm{ng} \mathrm{LH}$ added to serum were $110 \%, 101 \%, 90 \%, 96.5 \%, 91 \%$ and $97 \%$, respectively. Assay sensitivity was defined as the amount of standard at which binding of labelled hormone was $95 \%$ of that in assay tubes not containing standard and averaged $0.025 \mathrm{ng} /$ tube. Intra- and interassay coefficients of variation were $3.4 \%$ and $17.7 \%$, respectively.

Serum concentrations of prolactin were determined by the assay described by Pau \& Jackson (1984). Ovine prolactin antiserum (273-11) was used at an initial dilution of 1:100000. NIADDK-oPRL-I-1 was used as a standard and for radioiodination. Goat antirabbit gamma globulin was used at a working dilution of 1:40 (100 $\mu$ l) to precipitate bound hormone. Estimates of prolactin concentration were not influenced by sample volume $(25-200 \mu l)$. Recoveries of $0 \cdot 5,0 \cdot 8,1 \cdot 0$ and $1 \cdot 5 \mathrm{ng}$ prolactin added to serum were $90 \%, 102 \cdot 5 \%, 96 \%$ and $107 \%$, respectively. Assay sensitivity averaged $0.17 \mathrm{ng} /$ tube. Intra- and interassay coefficients of variation were $6.6 \%$ and $13.6 \%$, respectively.

Serum concentrations of cortisol were measured by a solid phase radioimmunoassay kit purchased from Diagnostic Products, Inc. (Los Angeles, CA, U.S.A.). Cross-reactivities for deoxycorticosterone and dexamethasone were $1.5 \%$ and $0.53 \%$, respectively. The assay was run according to the directions provided by the manufacturer except that the $0.5 \mathrm{ng}$ standard was diluted $\mathrm{l}: 1$ to provide an additional standard $(0.25 \mathrm{ng})$, and $50 \mu \mathrm{l}$ aliquants of serum were assayed. Estimates of cortisol concentration were not influenced by dilution of sample. Recoveries of 1 and $10 \mathrm{ng}$ cortisol from serum were $118 \%$ and $101.5 \%$, respectively. Intra- and interassay coefficients of variation were $7 \cdot 7 \%$ and $5 \cdot 2 \%$, respectively.

Statistical analyses. Reduction of radioimmunoassay data was performed by the computer program RIA AID (Robert Maciel Associates, Inc., Arlington, MS, U.S.A.) using a Compaq computer interfaced with a Micromedic Microstat gamma counter (Micromedic Systems Inc., Horsham, PA, U.S.A.). A four-parameter logistic curve (Rodbard \& Hutt, 1974) was used to describe the relationship between percentage binding of labelled hormone and $\log$ of the amount of standard.

Mean concentrations of prolactin were calculated for the first 5 sequential bleedings. Mean concentrations of $\mathrm{LH}$, LH pulse frequency (pulses $/ 4 \mathrm{~h}$ ) and LH pulse amplitude were calculated for all sequential bleedings. Pulses of LH were identified by a modification of the procedures described by Martin et al. (1983) and Schillo et al. (1985). Basal concentration of $\mathrm{LH}$ was defined as the mean of the three lowest concentrations encountered during each sequential bleeding. An LH pulse was defined as an increase in LH concentrations that consisted of a minimum of two values that exceeded the basal concentration by at least two within-assay standard deviations for LH concentrations comparable to the basai concentration.

Data for the first 5 sequential bleedings were subjected to analysis of variance for repeated measurements (Gill, 1978 ) to determine effects of group, surgery, bleeding (time) and appropriate interactions. If the group $\times$ time interaction was significant, then data from each group were subjected to separate analyses of variance using orthogonal polynomials to describe effects of time. If the surgery $\times$ time interaction was significant, then separate analyses of variance were done to determine effects of surgery at each time. If the group $\times$ surgery $\times$ time interaction was signifcant, then analyses of variance were done to determine effects of surgery in Groups I and II. In addition, effects of surgery were determined at each time for Groups I and II using $t$ tests (Gill, 1978). Data from the last sequential bleeding were subjected to analysis of variance for a $2 \times 2$ factorial design to determine effects of group, surgery and the group $\times$ surgery interaction.

\section{Results}

\section{ACTH challenge}

Injections of $40 \mathrm{U}$ ACTH stimulated cortisol release in sham-operated ewes, but not in adrenalectomized ewes (Fig. 2). Concentrations of cortisol were similar $(P>0 \cdot 1)$ for both groups 


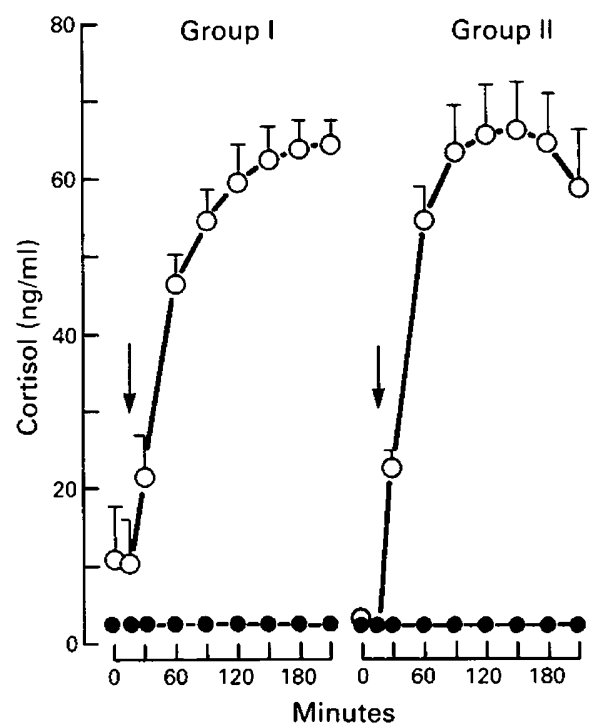

Fig. 2. Mean (+s.e.m.) concentrations of cortisol in ovariectomized ewes that were adrenalectomized $(\bullet)$ or sham-adrenalectomized $(O)$. Arrows designate times of injections of ACTH (40 U; i.m.).

of sham-operated ewes. Serum concentrations of cortisol were undetectable $(<2.5 \mathrm{ng} / \mathrm{ml})$ in adrenalectomized ewes both before and after ACTH, indicating that adrenalectomies were complete.

\section{Prolactin}

Serum concentrations of prolactin are shown in Fig. 3(a). Analysis of variance revealed a significant $(P<0.01)$ group $\times$ time interaction since the short days:long days sequence caused prolactin to decrease and then increase in Group I (quadratic effect of time; $P<0.01$ ), whereas the long days:short days sequence caused prolactin to decrease in a linear manner $(P<0.01)$ in Group II.

Concentrations of prolactin were significantly $(P<0.01)$ higher in adrenalectomized ewes than in sham-operated ewes. A significant $(P<0.01)$ surgery $\times$ time interaction was detected because the effects of adrenalectomy were significant $(P<0.05)$ during the first three sequential bleedings, but not during the last two sequential bleedings $(P>0.2)$.

\section{Luteinizing hormone}

Analysis of variance for mean concentrations of $\mathrm{LH}$ revealed significant surgery $\times$ time $(P<0.05)$ and group $\times$ time $(P<0.01)$ interactions. Mean concentrations of LH were higher in adrenalectomized ewes than in sham-operated ewes at $91(P=0.07)$, and $119(P<0.01)$ days (Fig. $3 \mathrm{~b})$. The group $\times$ time interaction was due to the fact that mean concentrations of $\mathrm{LH}$ increased in a quadratic manner $(P<0 \cdot 01)$ in Group II whereas the effect of time was not significant $(P>0 \cdot 1)$ for Group I.

Adrenalectomy did not influence frequency of LH pulses (Fig. 3c). However, analysis of variance revealed a significant $(P<0.01)$ group $\times$ time interaction due to the fact that photoperiod influenced LH pulse frequency in Group II, but not in Group I. Analysis of variance showed that the effects of time on frequency of LH pulses in Group II consisted of linear $(P<0.01)$, quadratic $(P<0.05)$ and cubic $(P<0.01)$ components because frequency of LH pulses decreased after exposure to long days for 56 days and then increased after exposure to short days for 66 days. 

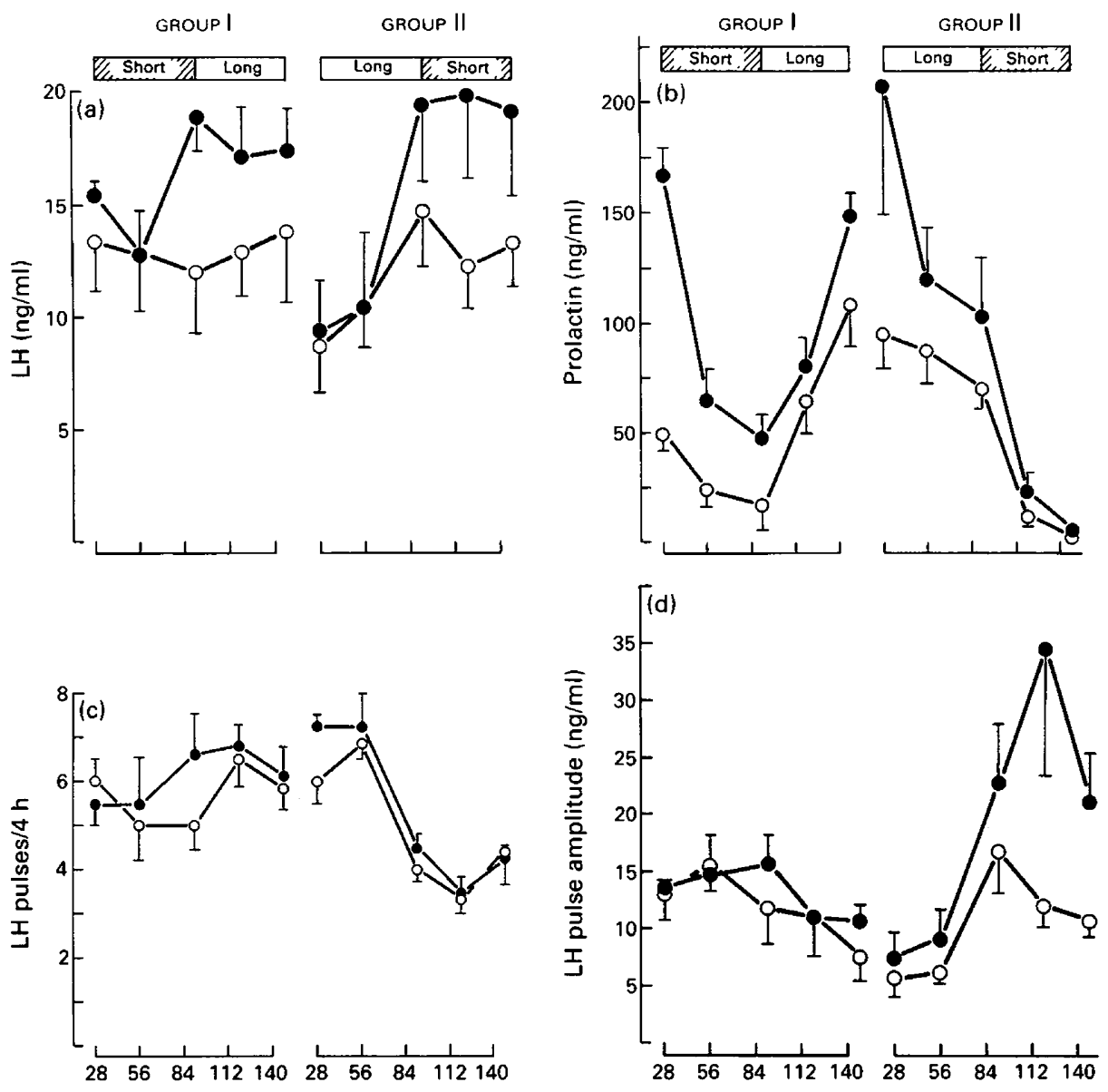

Day of experiment

Fig. 3. Mean ( \pm s.e.m.) concentrations of (a) prolactin and (b) LH, and (c) frequencies and (d) amplitudes of $\mathrm{LH}$ pulses in ovariectomized ewes that were adrenalectomized $(0)$ or shamadrenalectomized $(O)$ and subjected to different photoperiod sequences.

Amplitudes of LH pulses are shown in Fig. 3(d). Analysis of variance revealed significant effects of surgery $(P<0.05)$ as well as group $\times$ time $(P<0.01)$, surgery $\times$ time $(P<0.01)$ and group $\times$ surgery $\times$ time $(P<0.05)$ interactions. Amplitudes of LH pulses were higher $(P<0.05)$ in adrenalectomized ewes than in sham-operated ewes in Group II, but not in Group I $(P>0 \cdot 1)$. In Group II the effects of adrenalectomy on LH pulse amplitude were significant $(P<0.05)$ on Day 119.

In Group I, there was a small but significant $(P<0.01)$ decrease in LH pulse amplitude after exposure to short days. This effect of time consisted of both linear $(P<0.01)$ and quadratic $(P=0.05)$ trends. The effect of time was also significant $(P<0.01)$ in Group II and consisted of linear $(P<0.01)$, quadratic $(P<0.01)$ and cubic $(P<0.05)$ components since pulse amplitudes increased after exposure to long days for 56 days and then decreased after exposure to short days for 28 days.

Figure 4 shows characteristics of $\mathrm{LH}$ release 2 weeks after insertion of oestradiol implants. Adrenalectomy failed to influence mean concentrations of $\mathrm{LH}, \mathrm{LH}$ pulse amplitude and LH pulse frequency in the presence of oestradiol. Ewes exposed to short days (Group II) had higher 


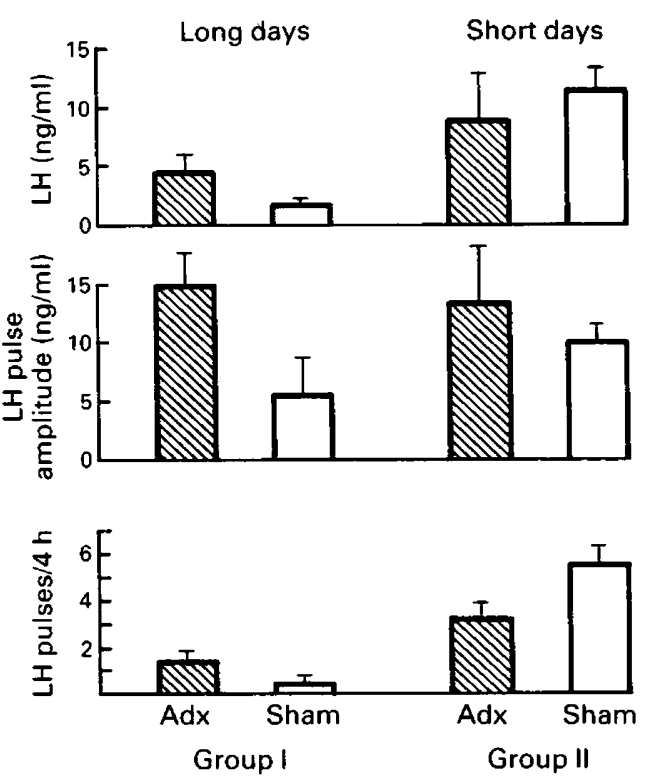

Fig. 4. Effects of daylength on mean ( \pm s.e.m.) concentrations of $\mathrm{LH}, \mathrm{LH}$ pulse amplitudes, and LH pulse frequencies 2 weeks after insertion of oestradiol implants in ovariectomized ewes adrenalectomized (Adx) or sham-adrenalectomized (sham).

$(P<0.01)$ mean concentrations of LH and higher $(P<0.01)$ frequencies of LH pulses than ewes exposed to long days (Group I). Amplitudes of LH pulses were similar $(P>0 \cdot 1)$ for both groups.

\section{Discussion}

Exposure of ovariectomized ewes to either natural or artificial long daylengths decreases frequency of LH pulses and increases amplitude of $\mathrm{LH}$ pulses, whereas exposure to short daylengths increases frequency of LH pulses and decreases amplitude of LH pulses (Goodman et al., 1982; Pau \& Jackson, 1985; Schillo et al., 1985). In the present study, a photoperiod sequence of short days followed by long days (Group I) did not influence LH release, whereas a sequence of long days followed by short days (Group II) influenced frequency and amplitude of LH pulses in ovariectomized ewes not treated with oestradiol.

Adrenalectomy did not abolish photoperiod-induced changes in LH release in Group II, suggesting that a sex steroid-independent mechanism is involved with mediating the effects of photoperiod on LH release in ewes. Our results agree with those of Montgomery et al. (1987) who showed that adrenalectomy did not influence patterns of LH release in ovariectomized ewes during the mid-anoestrous season. The existence of a truly steroid-independent mechanism could not be verified in our study because adrenalectomized ewes were given replacement therapy consisting of a mineralocorticoid and a glucocorticoid, steroids which might influence $\mathrm{LH}$ release. The results of Montgomery et al. (1987) suggest that deoxycorticosterone acetate acts as a progestagen and inhibits LH release in sheep. Photoperiod influenced LH release in ovariectomized, adrenalectomized hamsters not given steroid replacement therapy (Bittman \& Goldman, 1979), suggesting that a steroid-independent mechanism exists in this species.

At 28 and 56 days, ewes in Group II had high LH pulse frequencies and low LH pulse amplitudes due to the effects of prior exposure to short days. In these animals 56-91 days of exposure to long days was required to decrease pulse frequency and increase pulse amplitude, whereas 56 days 
of exposure to short days was required to increase pulse frequency and decrease pulse amplitude. These lags in response to artificial photoperiods are similar to those reported for ovariectomized ewes given oestradiol (Legan \& Karsch, 1980).

Patterns of LH in Group I did not reflect the photoperiod treatments imposed after adrenalectomy. Since ewes in Group I were exposed to natural long days ( $>12 \mathrm{~h}$ ) before entering the photochamber and were subjected to artificial long days before adrenalectomy, it is likely that these sheep became refractory to long days (Robinson et al., 1985) and therefore exhibited short-day patterns of LH release before exposure to artificial short days. This would explain the high $\mathbf{L H}$ pulse frequencies observed in these sheep on Day 28. The effects of long-day treatment on $\mathrm{LH}$ release in the absence of oestradiol are difficult to assess in Group I because responses were monitored for only 56 days and previous results suggest that approximately 90 days are required for a maximum response (Legan \& Karsch, 1980). However, patterns of LH in Group I in the presence of oestradiol ( 77 days of long-day treatment) indicate that these ewes did respond to the long photoperiod.

In the presence of oestradiol ewes exposed to short day lengths (Group II) had higher mean concentrations of LH and greater frequencies of LH pulses than did ewes exposed to long days (Group I). This is consistent with the observations of Goodman et al. (1982) and Martin et al. (1983). We did not detect a difference in amplitudes of LH pulses between oestradiol-treated ewes exposed to different daylengths. This disagrees with Goodman et al. (1982) who reported higher LH pulse amplitudes in oestradiol-implanted ewes exposed to long days, but agrees with Martin et al. (1983) who failed to detect seasonal changes in LH pulse amplitude in ovariectomized ewes treated with oestradiol.

Mean concentrations of $\mathrm{LH}$ increased in both groups of adrenalectomized ewes. This effect was due to an increase in LH pulse amplitude in Group II. We feel that these responses were probably not due to adrenalectomy per se because they occurred long after adrenal hormones would have been cleared from the circulation.

It is well established that long days increase and short days decrease circulating concentrations of prolactin in sheep (Pelletier, 1973; Pau \& Jackson, 1984). Our results in Groups I and II agree with these previous observations. The decrease in prolactin concentrations in Group II during long days was unexpected, but may have been due to random fluctuations in prolactin release. Subsequent exposure of Group II ewes to short days caused a precipitous decrease in prolactin as expected.

Adrenalectomy caused concentrations of prolactin to increase, suggesting that an adrenal product exerts an inhibitory effect on prolactin release. Glucocorticoids have been shown to inhibit prolactin release in rats (Harms et al., 1975; Euker et al., 1975) suggesting that these steroids could mediate adrenal inhibition of prolactin release in sheep. Although adrenalectomized sheep received daily injections of dexamethasone, it is possible that the resultant glucocorticoid activity in serum was too low to inhibit prolactin release. It is also possible that repeated administrations of this chemical caused a subsequent inhibition of prolactin release. This might explain the gradual decrease in the effect of adrenalectomy on prolactin concentrations.

In summary, adrenalectomy did not interfere with the effects of photoperiod on the LH pulse generator, suggesting that a sex steroid-independent mechanism may play a role in mediating the effects of photoperiod on LH release. Adrenalectomy did cause prolactin to increase indicating that the adrenal gland may exert negative feedback actions on release of this pituitary hormone.

We thank Dr Gary L. Jackson and Dr W. C. Wagner, University of Illinois, for prolactin antiserum and advice regarding adrenalectomies, respectively; Dr G. D. Niswender, Colorado State University, for LH antiserum; the National Hormone and Pituitary Program (NIADDK) for providing highly purified prolactin and LH; Mr Jeff Brockman, Ms Teresa McShane, Mr Stan Hileman and Dr Gary Newton for technical assistance; Ms Esther Collins for preparation of this manuscript. This research was supported by grants from the National Institute of Child Health 
and Human Development (20812-03 and 23345-01). This paper (no. 87-5-124) is published with approval of the director of the Kentucky Agricultural Experiment Station.

\section{References}

Abraham, G.E. (1974) Ovarian and adrenal contribution to peripheral androgens during the menstrual cycle. J. clin. Endocr. Metab. 39, 340-346.

Bittman, E.L. \& Goldman, B.D. (1979) Serum levels of gonadotrophins in hamsters exposed to short photoperiods: effects of adrenalectomy and ovariectomy. $J$. Endocr. 83, 113-118.

Euker, J.S., Meites, J. \& Riegle, G. D. (1975) Effects of acute stress on serum LH and prolactin in intact, castrated and dexamethasone-treated male rats. Endocrinology 96, 85-92.

Gill, J.L. (1978) Design and Analysis of Experiments in the Animal and Medical Sciences, Vol. 2. Iowa State University Press, Ames.

Goodman, R.L. \& Karsch, F.J. (1980) Pulsatile secretion of luteinizing hormone: differential suppression by ovarian steroids. Endocrinology 107, 1286-1290.

Goodman, R.L., Bittman, E.L., Foster, D.L. \& Karsch, F.J. (1982) Alterations in the control of luteinizing hormone pulse frequency underlie the seasonal variation in estradiol negative feedback in the ewe. Biol. Reprod. 27, 580-589.

Harms, P.G., Langlier, P. \& McCann, S.M. (1975) Modification of stress-induced prolactin release by dexamethasone or adrenalectomy. Endocrinology 96, 475-478.

Karsch, F.J., Foster, D.L., Goodman, R.L. \& Bittman, E.L. (1983) A role for estradiol in enhancing frequency of pulsatile luteinizing hormone secretion during the follicular phase of the estrous cycle of sheep. Endocrinology 113, 1333-1339.

Karsch, F.J., Cummins, J.T., Thomas, G.B. \& Clarke, I.J. (1987) Steroid feedback inhibition of pulsatile secretion of gonadotropin-releasing hormone in the ewe. Biol. Reprod. 36, 1207-1218.

Krieg, R.J., Lamberts, S.W.J. \& MacLeod, R.M. (1984) Paradoxical suppression of prolactin secretion: involvement of catecholaminergic mechanisms and the adrenal gland. Acta endocr. Copenh., 105, 463-467.

Legan, S.J. \& Karsch, F.J. (1980) Photoperiodic control of seasonal breeding in ewes: modulation of the negative feedback action of estradiol. Biol. Reprod. 23, 1061-1068.

Legan, S.J., Karsch, F.J. \& Foster, D.L. (1977) The endocrine control of seasonal reproductive function in the ewe: a marked change in response to the negative feedback action of estradiol on luteinizing hormone secretion. Endocrinology 101, 818-824.

MacDonald P.C. \& Siiteri, P.K. (1965) Origin of estrogen in women pregnant with an anencephalic fetus. $J$. clin. Invest. 44, 465-474.

Martin, G.B., Scaramuzzi, R.J. \& Henstridge, J.D. (1983) Effects of oestradiol, progesterone and androstenedione on the pulsatile secretion of luteinizing hormone in ovariectomized ewes during spring and autumn. J. Endocr. 96, 181-193.

Montgomery, G.W., Martin, G.B., Locatelli, A. \& Pelletier, J. (1987) Effect of adrenalectomy on LH release in sheep during the anoestrous season. $J$. Endocr. 114, 437-442.

Naftolin, F. \& Ryan, K.J. (1975) The metabolism of androgens in central neuroendocrine tissues. $J$. Steroid Biochem. 6, 993-997.

Niswender, G.D., Reichert, L.E., Jr, Midgley, A.R., Jr \& Nalbandov, A.V. (1969) Radioimmunoassay for bovine and ovine luteinizing hormone. Endocrinology 84, 1166-1173.

Pau, K-Y.F. \& Jackson, G.L. (1984) Effect of frontal hypothalamic deafferentation on photoperiodinduced changes in the secretion of prolactin in the ewe. Endocrinology 115, 1663-1671.

Pau, K-Y.F. \& Jackson, G.L. (1985) Effect of frontal hypothalamic deafferentation on photoperiodinduced changes of luteinizing hormone secretion in the ewe. Neuroendocrinology 41, 72-78.

Pelletier, J. (1973) Evidence for photoperiodic control of prolactin release in rams. J. Reprod. Fert. 35, 143-147.

Robinson, J.E., Wayne, N.L. \& Karsch, F.J. (1985) Refractoriness to inhibitory day lengths initiates the breeding season in the Suffolk ewe. Biol. Reprod. 32, 1024-1030.

Robyn, C. \& Tukumbane, M. (1983) Hyperprolactinemia and hirsutism. In Hirsutism and Virilism, pp. 189-204. Eds V. B. Mahesh \& R. B. Greenblatt. John Wright, Boston.

Rodbard, D. \& Hutt, D.M. (1974) Statistical analysis of radioimmunoassays and immunoradiometric (labeled antibody) assays: a generalized, weighted, iterative least squares method for logistic curve fitting. In Radioimmunoassay and Related Procedures in Medicine, Vol. 1, pp. 165-190. International Atomic Energy Agency, Vienna.

Schillo, K.K., Kuehl, D. \& Jackson, G.L. (1985) Do endogenous opioid peptides mediate the effects of photoperiod on release of luteinizing hormone and prolactin in ovariectomized ewes? Biol. Reprod. 32, $779-787$.

Thompson, F.N. \& Wagner, W.C. (1974) Fetal-maternal corticosteroid relationships in sheep during late pregnancy. J. Reprod. Fert. 41, 49-56.

Warren, J.C. \& Cheatum, S.G. (1967) Maternal urinary estrogen excretion: effects of adrenal suppression. $J$. clin. Endocr. Metab. 27, 433-436.

Received 5 October 1987 